Case Report

\title{
TUBERCULAR TENOSYNOVITIS OF EXTENSOR TENDONS OF WRIST: AN UNUSAL PRESENTATION
}

Dawadi TP ${ }^{1}$,Subedi $N^{2}$,Poudel $D^{3}$, Bista $\mathrm{Y}^{4}$,Panthi $\mathrm{P}^{5}$

${ }^{1,2}$ Department of Orthopedics, Manmohan Memorial Teaching Hospital, Swoyambhu, Kathmandu, Nepal

3,Department of Pathology, Manmohan Memorial Teaching Hospital, Swoyambhu, Kathmandu, Nepal

${ }^{4}$ Department of Radiology, Manmohan Memorial Teaching Hospital, Swoyambhu, Kathmandu, Nepal

${ }^{5}$ Department of Pathology, Bhaktapur Cancer Hospital, Bhaktapur, Nepal

${ }^{\dagger}$ Corresponding author: dtejprakash@yahoo.com

DOI: $\underline{\text { https://doi.org/10.3126/jmmihs.v7i1.43153 }}$

\section{ABSTRACT}

Background: Tubercular Tenosynovitis is a very rare disease and even rare to involve extensor tendons. The clinical picture is typical and confirmation is done by histopathology.

Case Presentation: We present a rare case of soft tissue swelling at dorsum of wrist and distal forearm since six months. On Ultrasonogram, there were multiloculated cystic collections surrounding the extensor tendons. Lab parameters showed increased ESR and Mantoux test was positive. With the provisional diagnosis of Tenosynovitis, debulking tenosynovectomy was done where melon seed bodies were seen. Histopathology confirmed granulomatous lesions with caseous necrosis and Acid Fast Bacilli stain was also positive for the biopsy tissue. He responded to our anti-tubercular drugs with full range of motion after two months of surgery and no recurrence of swelling at four year follow up.

Conclusion: Typical clinical picture, intra operative findings of melon seed bodies and rice bodies and histopathological confirmation of granulomatous lesions with caseous necrosis are pathognomonic of Tubercular Tenosynovitis. Complete debulking and antitubercular drugs cure the disease and prevents recurrence. 
Keywords: Tubercular Tenosynovitis, Ultrasonogram, Mantoux test, Granulomatous lesion, Caseous Necrosis, Acid Fast Bacilli

\section{INTRODUCTION}

Musculoskeletal Tuberculosis is a rare disease, accounting for $10 \%$ of the extrapulmonary tuberculosis. In wrist and hand, the flexor tendons and the radio ulnar bursa are commonly affected sometimes compressing the median nerve. However involvement of dorsal wrist compartments and tendon sheaths are rare. ${ }^{2}$ The diagnosis is usually delayed due to multiple similar conditions as well as difficulty in diagnosis.

\section{Case report:}

A 60 years old Nepali man presented to us with 6 months history of progressive, initially painless and later painful swelling at wrist and distal forearm dorsum. The pain was mild, dull aching, persistent,5/10 in intensity and increasing with movement of wrist and thumb, decreasing with rest and medications. There was no history of trauma, fever, night sweats or any pain in other joints. However he had loss of appetite and progressive loss of weight. The patient had no history of any Tuberculosis, Diabetes Mellitus, Hypertension, any surgery in the past. The physical examination revealed average built middle aged man with right wrist swelling $10 \times 5 \mathrm{~cm}$ extending to distal forearm dorsum specially at the dorsolateral aspect. It was non tender, non-compressible, but multiloculated mobile only in plane perpendicular to wrist. Lab findings showed normal blood count, increased ESR, and CRP. Mantoux test was positive. There was visible soft tissue swelling on $\mathrm{X}$ ray of wrist and $\mathrm{X}$ ray of chest showed opacities in the apical region of left chest. Sputum for AFB was negative. Ultrasonography of wrist showed multiloculated cystic swelling surrounding the tendons at wrist and distal forearm.

Under brachial plexus block with tourniquet, excisional biopsy was done. Thickening of the tendon sheaths of ECRL, ERB and EPL with yellowish fluid and multiple yellowish melon seed bodies and rice bodies were seen. However, wrist joint was spared. Tenosynovectomy was done and specimen was sent for histopathological examination and AFB staining. 


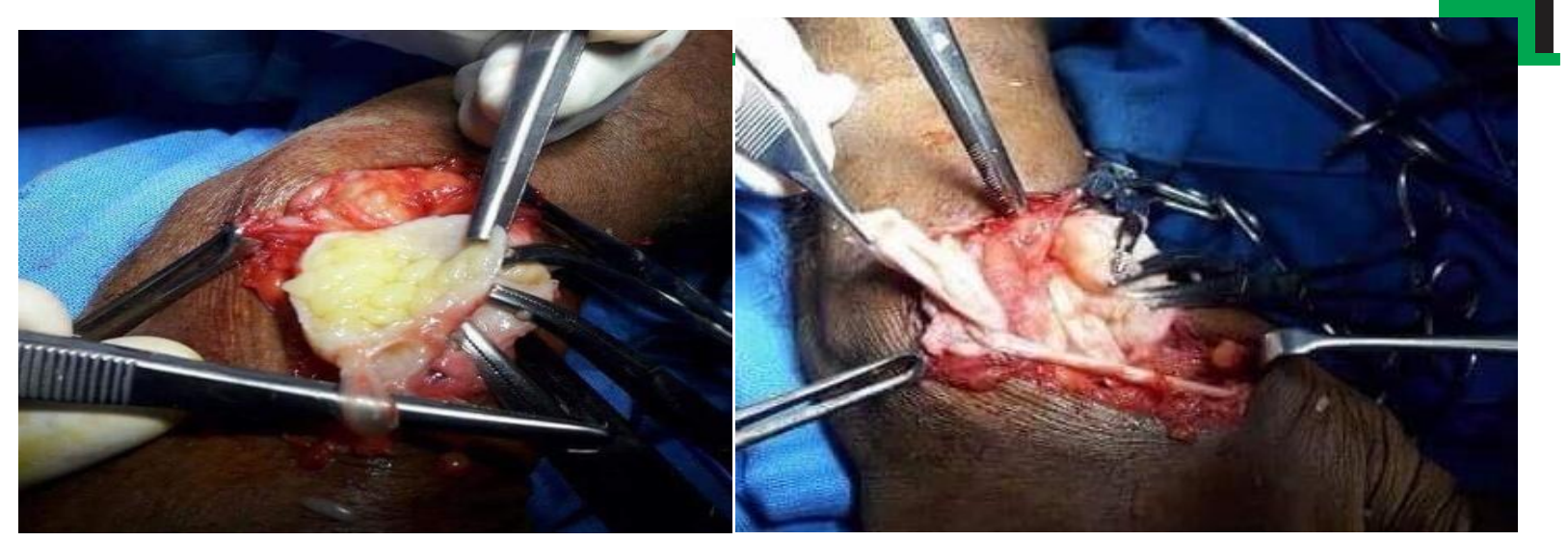

Pic1: Thickened tendon sheath with

Pic 2. Involvement of EPL, ECRL and ECRB

melon seed and rice body

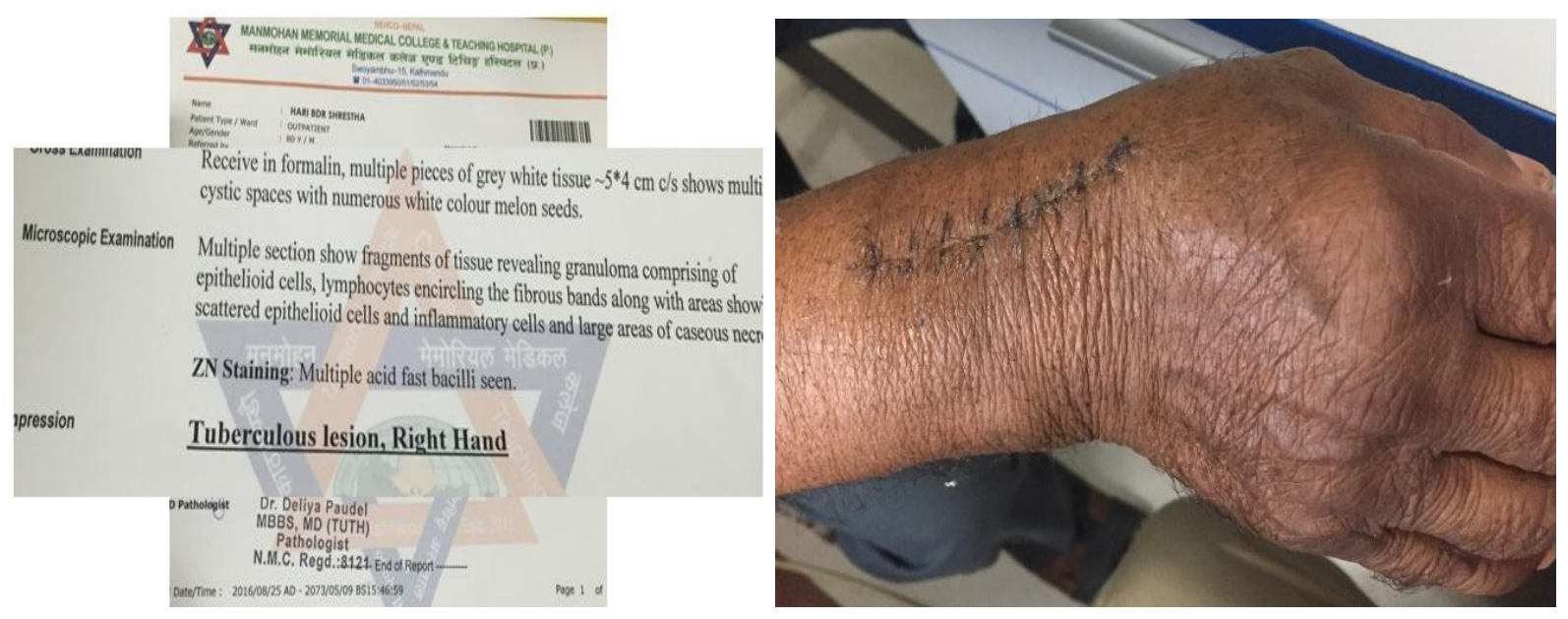

Pic 3. Histopath report

Pic 4. Healed scar at 2 weeks

Volar slab extending to thumb was given for 3 weeks as hook of EPL at listers tubercle had to be augmented due to enlargement and degeneration of the compartment sheath from inflammatory tissue. Histopathology showed epithelial granuloma with minimal caseous necrosis and Langhans giant cells. Biopsy tissue was positive for AFB stain. Antitubercular drugs were started and patient became normal in 2 months with full range of motion of wrist. After nine months of completion of ATT, the disease healed in terms of wrist and pulmonary lesions with no relapse at three year follow up. 


\section{DISCUSSION}

Tuberculosis is one of the top ten leading causes of death worldwide. About one third of the world's population is infected by Mycobacterium tuberculosis and 10\% of infected persons will develop TB disease at some time in their lives. The commonly affected extra-pulmonary sites of TB are Lymph nodes, Genitourinary Tracts, Bone Marrow, CNS and Musculoskeletal system which includes bones, joints, tendons. ${ }^{3}$

Tuberculous tenosynovitis of the wrist or Compound Palmer Ganglion is an uncommon lesion that requires early recognition and treatment for the best possible prognosis. There are two theories regarding the pathogenesis of the tuberculosis of wrist, direct inoculation and hematogenous dissemination form the primary focus. ${ }^{4}$ Tubercular tenosynovitis is more common in upper limb. Tubercular Tenosynovitis selectively targets wrist and volar aspect of hand. However the digital flexor sheath and the dorsal wrist compartment are affected less often. ${ }^{5}$ Because of its rarity, insidious onset and slow progressionof swelling, the diagnosis and confirmation of the clinical entity is delayed. The precipitating factors include trauma, overuse of the joint, old age, low socioeconomic status, malnutrition, alcoholism, immunosuppression and steroid injections. ${ }^{6}$ Tendon rupture is a rare presentation, but it may occur when treatment is delayed. ${ }^{7}$

The routine laboratory investigations are nonspecific and often noncontributory. ${ }^{\mathbf{8}}$ The radiograph of chest and wrist are usually normal. MRI showsnon-specific synovitis in Hygromatous stage, thickened synovium with low signal intensity material within the synovial fluid in the Serofibrinous stage on T2 images and tendon involvement manifested by tendon thinning, tethering, or disruption may be seen during this stage. Extension beyond the tendon sheath with enhancing soft tissue mass formation is characteristic of the Fungoid stage. In contrast to acute suppurative tenosynovitis, where synovial sheath fluid is the predominant feature, relatively little synovial sheath fluid is characteristic of tuberculous pathology. ${ }^{9}$

There are three stages of disease depending on the duration of the disease, resistance and the virulence of the organism. In the earliest stage, the tendon is replaced by vascular granulation tissue. Later on, the sheath is obliterated by fibrous tissue. Fluid is confined within the sheath 
and rice bodies may appear due to caseation and tendon may rupture spontaneously. If healing by fibrous tissue formation fails to curtail the pathologic process, extensive caseation and granulation occur. This may lead to sinus formation and superimposed secondary infection. ${ }^{\mathbf{1 0}}$

Rice bodies or Melon seeds are seen in 50\% of tubercular synovitis cases and are highly suggestive. The rice body formation may be due to microinfarction after intraarticular synovial inflammation or de novo formation and progressive enlargement by fibrin.11 Differentialdiagnoses of tubercular tenosynovitis include other mycobacterial infections, pyogenic infection, brucellosis, nonspecific tenosynovitis, foreign body tenosynovitis, sarcoidosis, rheumatoid arthritis, gouty arthritis, pigmented villonodular synovitis of the tendon sheath, and fungus infection. ${ }^{7}$ The positive retroflexion sign comparing extension of the thumb toward the roof while the palms lie flat on the table, as described by Skoff, is useful to clinch the diagnosis of EPLrupture if present. ${ }^{\mathbf{1 2}}$

Antitubercular drugs along with tenosynovectomy gives excellent result and prevent recurrence of disease. Some prefer complete excision of the tendon sheath while others advocate decompression only. In our case, complete debridement of involved tissue with augmentation of hitch of EPL at Listers Tubercle ie, third compartment because of enlargement and degeneration from the inflammatory tissue. After three weeks of wrist splintage followed by active ROM, full ROM was achieved at 2 months of surgery and with 9 months of ATT, the patient had disease free interval of more than four year when seen at last follow up. The QUICK DASH score was satisfactory (18.18) before surgery while at last follow up after four years it was good (11.36). Close follow up is required as Tubercular Synovitis has more than $50 \%$ local recurrence after treatment within a year. ${ }^{13}$

\section{CONCLUSION}

Though uncommon, any soft tissue swelling around wrist should raise suspicion of Tubercular Tenosynovitis. Insidious onset, slow growing swelling at wrist with increased ESR and positive Mantoux test in tropical countries like Nepal, positive typical Millet seeds or Melons seed and rice bodies on excision and positive Acid Fast Bacilli on Ziehl Neelson staining along 
with Tubercular granulomas with caseous necrosis on histopathology confirms the diagnosis. Early diagnosis and complete excision of diseased tissue with antitubercular drugs give good functional outcome and prevents recurrence of disease. Since definite diagnosis is difficult and histological examination may not always show definite cause of the swelling, regular follow up of the case is mandatory.

Disclosure: None

Written informed consent obtained from the patient.

\section{REFERENCES}

1. Leonard MK, Blumberg HM. Musculoskeletal Tuberculosis. Microbiol Spectr. 2017 Apr;5(2).

2. Bickel WH, Kimbrough RF, Dahlin DC. Tuberculous tenosynovitis. J Am Med Assoc. 1953 Jan 3;151(1):31-5.

3. Higuchi S, Ishihara S, Kobayashi $\mathrm{H}$, Arai T. A mass lesion of the wrist: a rare manifestation of tuberculosis. Intern Med Tokyo Jpn. 2008;47(4):313-6.

4. Hodgson AR, Smith TK, Gabriel Sister null. Tuberculosis of the wrist.With a note on chemotherapy.ClinOrthop. 1972 Apr;83:73-83.

5. Anoumou MN. Tuberculosis tenosynovitis of the flexor tendons in the wrist: a case report. ACTA OrthopTraumatolTurc. 2014;48(6):690-2.

6. Mrabet D, Ouenniche K, Mizouni H, Ounaies M, Khémiri C, Sahli H, et al. Tuberculosis tenosynovitis of the extensor tendons of the wrist. BMJ Case Rep. 2011 Aug 31;2011.

7. Jaovisidha S, Chen C, Ryu KN, Siriwongpairat P, Pekanan P, Sartoris DJ, et al. Tuberculous tenosynovitis and bursitis: imaging findings in 21 cases. Radiology. 1996 Nov;201(2):507-13.

8. Rampal K, Prajapati DK, DeenDayalUpadhya Hospital, Hari Nagar, New Delhi, India., Sharma M, CHC, Kasel, Tarn Taran, Punjab, India., Indoliya RK, et al. Tubercular Tenosynovitis of Extensor Tendon of Wrist Mimicking a Ganglion. Int J Integr Med Sci. 2016 Jun 30;3(6):318-20.

9. Sanders CJ, Schucany WG. Tuberculous tenosynovitis.:2.

10. Lall H, Nag SK, Jain VK, Khare R, Mittal D. Tuberculous extensor tenosynovitis of the wrist with extensor pollicislongus rupture: a case report. J Med Case Reports [Internet]. 2009 Dec [cited 2018 Dec 2];3(1). Available from: http://jmedicalcasereports.biomedcentral.com/articles/10.1186/1752-1947-3-142

11. Chen A, Wong L-Y, Sheu C-Y, Chen B-F. Distinguishing multiple rice body formation in chronic subacromial-subdeltoid bursitis from synovial chondromatosis.Skeletal Radiol. 2002;31(2):119-121.

12. Skoff HD. Postfracture extensor pollicislongus tenosynovitis and tendon rupture: a scientific study and personal series. Am J Orthop Belle Mead NJ. 2003;32(5):245-247.

13. Regnard P-J, Barry P, Isselin J. Mycobacterial Tenosynovitis of the Flexor Tendons of the Hand: A report of five cases. J Hand Surg. 1996 Jun;21(3):351-4. 